\title{
ESR studies of superconducting cuprates: Low magnetic field effects at X-band and $300 \mathrm{MHz}$
}

\author{
R JANES*, P P EDWARDS*, R S LIU*, A D STEVENS** and \\ M C R SYMONS** \\ * Interdisciplinary Research Centre in Superconductivity, University of Cambridge, \\ West Cambridge Site, Madingley Road, Cambridge CB3 OHE, UK \\ **Department of Chemistry, The University, Leicester LEI 7RH, UK
}

\begin{abstract}
Low field microwave absorption in cuprate superconductors below $T_{c}$ is reported in a range of materials using ESR spectrometers operating at X-band and $300 \mathrm{MHz}$. The radiofrequency apparatus facilitated a detailed study of the $0-100 \mathrm{G}$ region where the absorption is most intense and we include here a brief discussion of the effects of incident microwave power and sample temperature on the intensity and position of the signal.
\end{abstract}

Keywords. ESR; EPR; superconductivity cuprates.

\section{Introduction}

The superconducting state in the high- $T_{c}$ copper oxide-based materials is characterized by the appearance of an intense, broad, low-field microwave absorption at temperatures below the critical value, which may be conveniently studied using conventional electron spin resonance (ESR) methodology (see for example Blazey et al 1987; Jones et al 1990). Most current interpretations of this signal centre around the inherent granular nature of these materials and the production of intergrain Josephson currents (Shrivastava 1988). It should also be noted that similar absorptions have been detected in small particles of $\mathrm{Nb}$, the "Cheverel phase" $\mathrm{PbMo}_{6} \mathrm{~S}_{8}$ (Blazey et al 1989) and more recently in granular superconducting aluminium films (Suss et al 1989). In this study we discuss the observation of the signal at X-band and using a spectrometer operating at a fixed frequency of $300 \mathrm{MHz}$, the latter enabled us to analyse in detail the $0-100 \mathrm{G}$ region and lends itself to the study of low-field absorption in superconductors, which occur in a magnetic field regime where larger electromagnets are somewhat inaccurate. A number of groups have used externally fed Helmholtz coils to compensate for residual fields, by providing field in the direction opposite to that of the main magnet (Peric et al 1988; Harutyunyan et al 1988). Clearly the radiofrequency spectrometer provides an alternative solution to this problem. Studies at both frequencies were carried out on a range of samples having various compositions, and we report here an analysis ( $^{r}$ the signal amplitude, lineshape and position as a function of composition and sample temperature. We also show how the microwave absorption disappears above a sample-dependent threshold power level, a response which is reversible and always accompanied by extensive detuning of the spectrometer, apparently consistent with the material being driven into the 
normal state. Many examples of this signal have been reported at X-band, but this is the first study at $300 \mathrm{MHz}$.

\section{Experimental}

The samples studied here were prepared by standard solid-state synthesis or co-precipitation techniques from high purity reagents, and had the following compositions: $\mathrm{YBa}_{2} \mathrm{Cu}_{3} \mathrm{O}_{y}, \mathrm{GdBa}_{2} \mathrm{Cu}_{3} \mathrm{O}_{y}, \mathrm{ErBa}_{2} \mathrm{Cu}_{3} \mathrm{O}_{y}$, members of the $\mathrm{Tl}-\mathrm{Ca}-\mathrm{Ba}-\mathrm{Cu}-\mathrm{O}$ and $\mathrm{Bi}-\mathrm{Ca}-\mathrm{Sr}-\mathrm{Cu}-\mathrm{O}$ systems, $\mathrm{Tl}_{2} \mathrm{CeBa}_{2} \mathrm{Cu}_{2} \mathrm{O}_{y}$ and $\left(\mathrm{Tl}_{0.5} \mathrm{~Pb}_{0.5}\right)\left(\mathrm{Ca}_{0.8} \mathrm{~A}_{0.2}\right) \mathrm{Sr}_{2} \mathrm{Cu}_{2} \mathrm{O}_{y}$ where $\mathrm{A}=\mathrm{Y}$ or Er. A standard four-point probe method was used for electrical resistance measurements. A.C. magnetic susceptibility was measured by a mutual inductive technique, employing a frequency of $823 \mathrm{~Hz}$. Crystal structures were determined by X-ray diffraction (Spectrolab CPS-120 diffractometer). ESR was measured at X-band using a Bruker ER200D spectrometer and a homebuilt $300 \mathrm{MHz}$ system (Brivati et al 1989). The instrumental sensitivity was ca. $1 \cdot 2 \times 10^{17}$ spins/Gauss compared with ca. $10^{11}-10^{12}$ spins/Gauss for the $\mathrm{X}$-band spectrometer. Measurements using the $300 \mathrm{MHz}$ spectrometer were carried out at $77 \mathrm{~K}$ by placing a standard high-quality quartz ESR tube containing the sample into a quartz Dewar filled with liquid nitrogen, which in turn was suspended in the quartz cavity Dewar. Temperatures above $77 \mathrm{~K}$ were measured by removing the coolant and allowing the sample to warm (ca. $2 \mathrm{~K} / \mathrm{min}$ ) with the temperature being constantly monitored by a thermocouple located adjacent to the sample, within the ESR tube.

\section{Results and discussion}

\subsection{Measurements at $77 \mathrm{~K}$}

X-band ESR measurements revealed all the materials used in this study to be superconducting at $77 \mathrm{~K}$, evidence by the appearance of a characteristic low-field absorption. This was generally very intense and only small amounts of sample were required to produce a detectable signal $(0.1 \mathrm{~g})$ even when using the less sensitive r.f. spectrometer. The spectrum shown in figure 1 is an extreme example of this, showing the low-field absorption at $\mathrm{X}$-band, from a tiny single crystal of $\mathrm{Tl}_{2} \mathrm{Ca}_{2} \mathrm{Ba}_{2} \mathrm{Cu}_{3} \mathrm{O}_{y}$, with a superconducting transition temperature of $118 \mathrm{~K}$, and a mass of ca. $1 \times 10^{-5} \mathrm{~g}$ clearly illustrating the sensitivity of the technique, which on a practical level, has rendered ESR a quick and efficient method of routinely screening samples for superconductivity. Figure 2 shows a scanning electron microscope image of these crystals, revealing a plate-like habit. Blazey et al (1988) reported the observation of regularly spaced absorption lines in the low-field absorption of $\mathrm{YBa}_{2} \mathrm{Cu}_{3} \mathrm{O}_{y}$ single crystals, this was particularly evident at liquid helium temperatures and low microwave power levels. The periodicity of the pattern was assigned to macroscopic flux quantisation being related to the sample dimensions. It should be noted that no such signals were detected from the single crystals studied here, even at the lowest attainable microwave power level $(200 \mathrm{~W})$ - although the spectrum clearly becomes very noisy in the $0-1000 \mathrm{G}$ region (figure 1) which may, at least, in part be due to 
magnetic fields emanating from external laboratory sources (Tyagi and Barsoum 1988).

Figures 3-6 show the low-field signal at $77 \mathrm{~K}$ from a range of $\mathrm{Bi}$ and $\mathrm{Tl}$-based materials, clearly showing the intersample variability of the lineshape and width. Specifically, in some samples a distinct upturn in the spectrum from zero-field to some maximum value $(\mathrm{d} P / \mathrm{d} H)$ is observed, whereas others yield a signal which

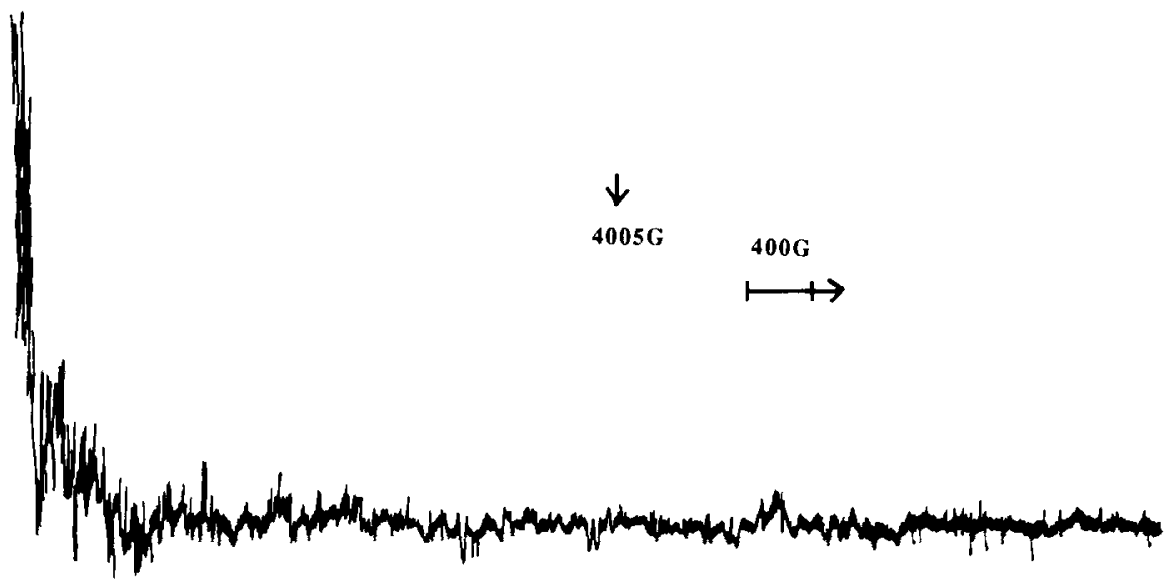

Figure 1. Low field microwave absorption for a single crystal of $\mathrm{Tl}_{2} \mathrm{Ca}_{2} \mathrm{Ba}_{2} \mathrm{Cu}_{3} \mathrm{O}_{y}$, with a $T_{c}$ of $118 \mathrm{~K}$, measured at $77 \mathrm{~K}$ by an X-band ESR spectrometer.

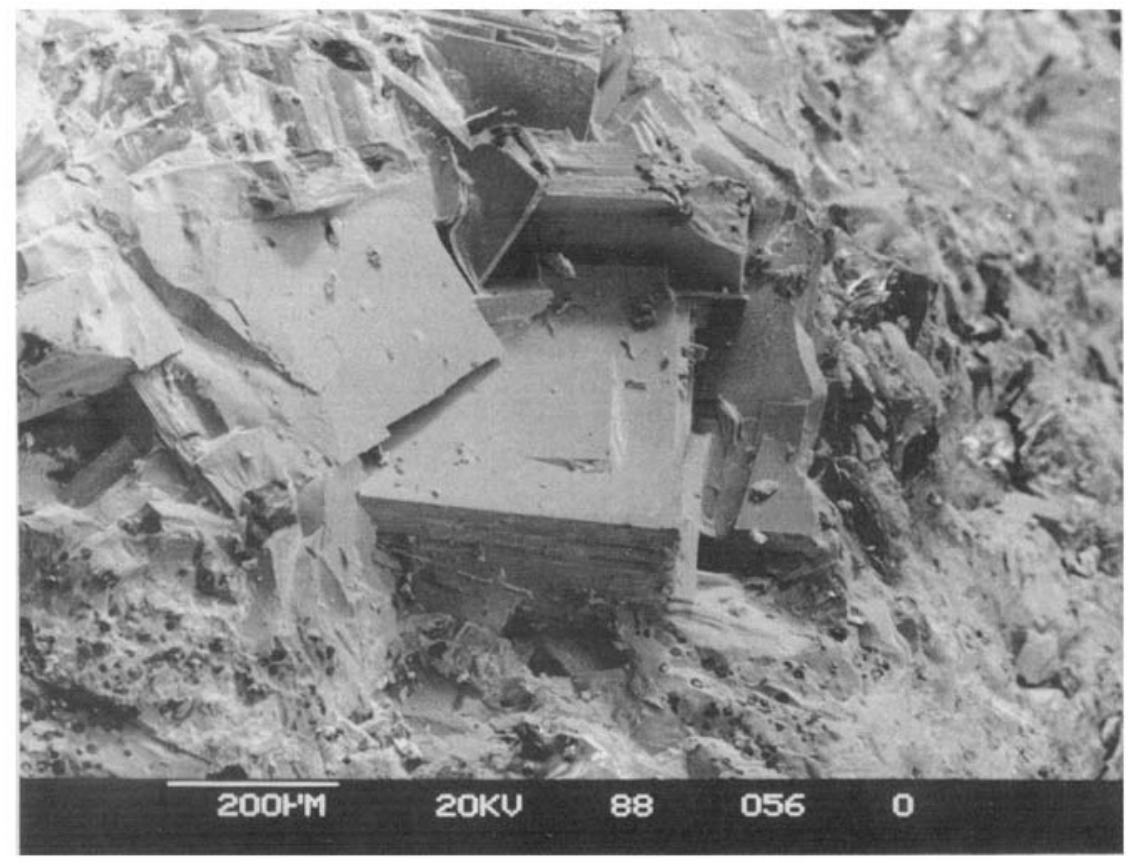

Figure 2. Scanning electron microscope image of $\mathrm{Tl}_{2} \mathrm{Ca}_{2} \mathrm{Ba}_{2} \mathrm{Cu}_{3} \mathrm{O}_{y}$ single crystals. 


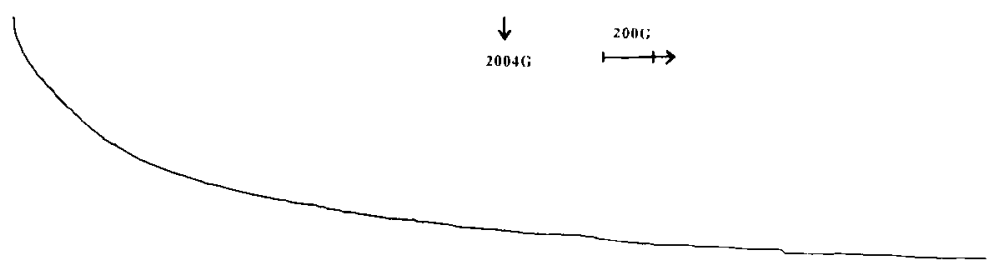

Figure 3. Low-field microwave absorption $(9 \cdot 1 \mathrm{GHz})$ for $\mathrm{Bi}_{2} \mathrm{CaSr}_{2} \mathrm{Cu}_{2} \mathrm{O}_{y}$ having a $T_{c}$ of $80 \mathrm{~K}$. (sample temperature $=77 \mathrm{~K}$ ).

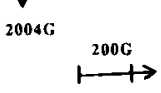

Figure 4. Low-field microwave absorption $(9 \cdot 1 \mathrm{GHz})$ for the mixed phase material (with a $T_{c}$ of $\left.110 \mathrm{~K}\right):(\mathrm{Bi}, \mathrm{Pb})_{2} \mathrm{Ca}_{2} \mathrm{Sr}_{2} \mathrm{Cu}_{3} \mathrm{O}_{y}(90 \%)$ and $(\mathrm{Bi}, \mathrm{Pb})_{2} \mathrm{CaSr}_{2} \mathrm{Cu}_{2} \mathrm{O}_{y}(10 \%)$ measured at $77 \mathrm{~K}$.

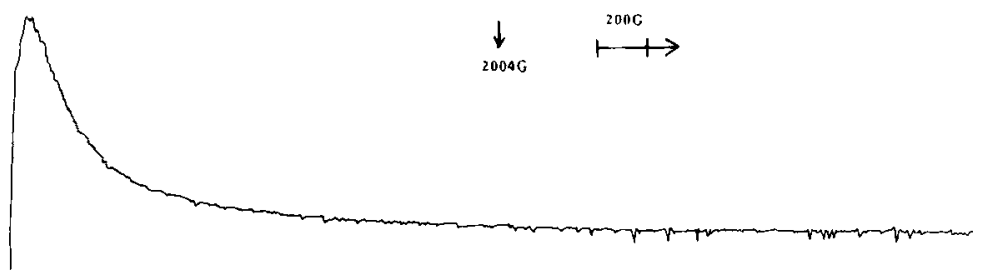

Figure 5. Low-field microwave absorption $(9 \cdot 1 \mathrm{GHz})$ for $\mathrm{Tl}_{0.5} \mathrm{~Pb}_{0.5} \mathrm{Ca}_{0.8} \mathrm{Er}_{0.2} \mathrm{Sr}_{2} \mathrm{Cu}_{2} \mathrm{O}_{y}$ $\left(T_{c}=110 \mathrm{~K}\right)$ measured at $77 \mathrm{~K}$.

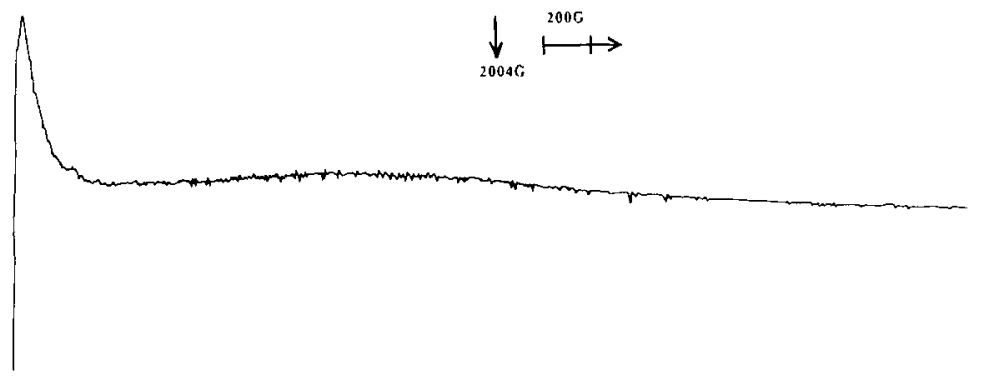

Figure 6. Low.field microwave absorption $(9 \cdot 1 \mathrm{GHz})$ for the mixed phase material: $\mathrm{Tl}_{2} \mathrm{Ca}_{2} \mathrm{Ba}_{2} \mathrm{Cu}_{3} \mathrm{O}_{y}(95 \%)$ and $\mathrm{Tl}_{2} \mathrm{CaBa}_{2} \mathrm{Cu}_{2} \mathrm{O}_{y}(5 \%)$ measured at $77 \mathrm{~K}\left(T_{c}=118 \mathrm{~K}\right)$. 


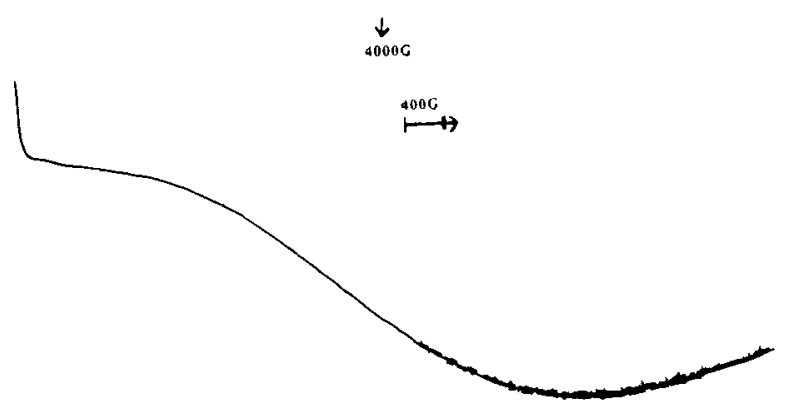

Figure 7. Low-field microwave absorption $(9 \cdot 1 \mathrm{GHz})$ for a single crystal sample of $\mathrm{Bi}_{2} \mathrm{CaSr}_{2} \mathrm{Cu}_{2} \mathrm{O}_{y}\left(T_{c}=80 \mathrm{~K}\right)$ measured at $77 \mathrm{~K}$.

originates from a maximum value. The $\mathrm{Bi}_{2} \mathrm{CaSr}_{2} \mathrm{Cu}_{2} \mathrm{O}_{y}$ single crystal (figure 7) with $T_{\mathrm{c}}=80 \mathrm{~K}$, was a particularly striking example, exhibiting an initial absorption over ca. $300 \mathrm{G}$ followed by a very broad signal stretching over ca.8000 G. We do not intend to attempt to rationalize this clearly very complex problem here but rather refer to the work of Lue and Wu (1989) who have recently simulated this response and calculated values of coherence lengths, superconducting electron density and granular size from the observed lineshapes. In addition Shrivastava (1988) discusses the microwave signal in terms of the circulation of Josephson currents within domains whose size distribution is mirrored by the signal lineshape and calculated the domain length corresponding to the signal maxima. In addition, in our work we observed that the spectra frequently exhibit a series of apparently discrete absorptions superimposed on the broad signal (figures 5 and 6 ) in all cases a repeat scan over the same field range was carried out to ensure reproducibility. These lines are similar to those detected by Shrivastava (1988) in samples of $\mathrm{ErBa}_{2} \mathrm{Cu}_{3} \mathrm{O}_{y}$ and $\mathrm{YBa}_{2} \mathrm{Cu}_{3} \mathrm{O}_{y}$, who discusses them in terms of flux quantized energy oscillations. In addition, Tyagi and Barsoum (1988) observed similar reproducible sub-structure from $\mathrm{YBa}_{2} \mathrm{Cu}_{3} \mathrm{O}_{y}$.

\subsection{Studies at $300 \mathrm{MHz}$ : Effect of sample temperature}

As stated earlier, an operating frequency of $300 \mathrm{MHz}$ enabled us to carefully calibrate the $0-100 \mathrm{G}$ region, and in particular allowed us to study the effect of sample temperature on the low-field response, an example of which is shown in figure 8. This spectrum clearly shows that the absorption occurs from the lowest measurable field values and qualitatively the signal resembles that observed at $X$-band, clearly supporting the assignment of Lin et al (1988) to a non-resonant effect. For all the samples studied, a progressive shift of the peak maxima to lower fields was observed on warming, and because the r.f. field was accurately locked at $300 \mathrm{MHz}$ we do not believe this effect is due to changes in the cavity-resonant frequency. Occurring simultaneously with the lineshift, the strength of the signal initially increased, then decayed gradually until disappearing below the instrumental detection limits above $T_{c}$. The initial enhancement of the signal is somewhat surprising and difficult to explain, being inconsistent with the results of Shrivastava (1988) who defines a $\left(T_{c}-T\right)^{2 \cdot 7}$ variation of signal intensity close to $T_{c}$. 


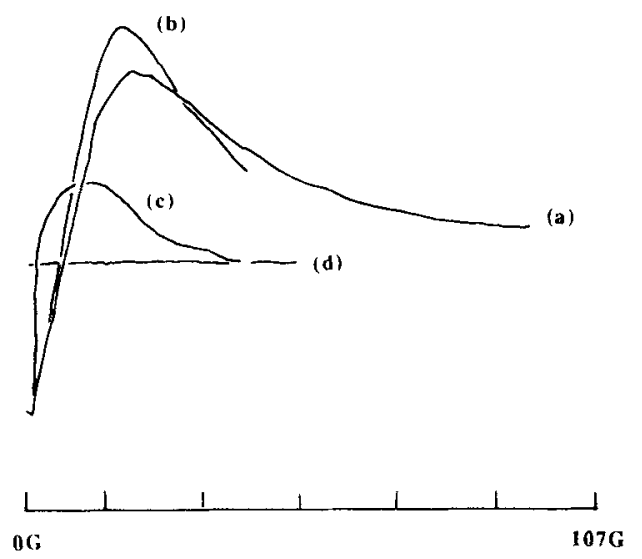

Figure 8. Low field absorption measured at $300 \mathrm{MHz}$ for a powdered sample of $\mathrm{YBa}_{2} \mathrm{Cu}_{3} \mathrm{O}_{y}$ $\left(T_{c}=93 \mathrm{~K}\right.$ ) measured at a range of temperatures, (a) $77 \mathrm{~K}$, (b) ca. $81 \mathrm{~K}$, (c) ca. $86 \mathrm{~K}$ and (d) ca. $95 \mathrm{~K}$.

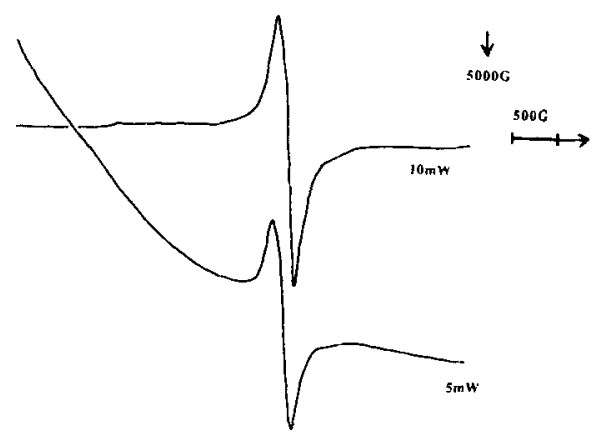

Figure 9. Effect of incident microwave power on the low-field absorption for a sample of $\mathrm{Tl}_{2} \mathrm{CeBa}_{2} \mathrm{Cu}_{2} \mathrm{O}_{y}\left(T_{c}=90 \mathrm{~K}\right)$ measured at $77 \mathrm{~K}$.

\subsection{Effect of microwave power}

By increasing the incident power level (in the $\mathrm{mW}$ regime) we observed in all the samples studied, an initial enhancement and then a sudden loss of the signal at a sample-dependent threshold value, a response which was found to be reversible on attenuation. Significantly, we observed a concomitant detuning of the microwave bridge evidenced by a shift of the diode current. Since an automatic frequency control circuit was used to lock the klystron to the cavity resonant frequency, the detuning can be attributed to a $Q$-change for the loaded cavity, consistent with the generation of free-carriers. It therefore appears that the increased power drives the material from superconducting, into the normal state, even at temperatures well below $T_{c}$. Figure 9 shows the results for a sample of $\mathrm{Tl}_{2} \mathrm{CeBa}_{2} \mathrm{Cu}_{2} \mathrm{O}_{y}\left(T_{c}=90 \mathrm{~K}\right)$ where $10 \mathrm{~mW}$ of power 
is sufficient to effect a transition back to the normal state. Most current theories of this response pinpoint the supercurrent induced by the external applied field (due to the Meissner effect) and the consequent Josephson microtunneling between grains as its source. We may speculate that the loss of signal at high power levels observed here, is simply a result of exceeding the critical current value $\left(J_{c}\right)$ and is therefore consistent with the observed sample-to-sample variation. It would clearly be of interest to correlate our results with samples having known $J_{c}$ values e.g. $\mathrm{YBa}_{2} \mathrm{Cu}_{3} \mathrm{O}_{y}$ with different microcrystalline structures.

\section{References}

Blazey K W, Muller K A, Bednorz J G, Berlinger W, Amoretti G, Buluggiu E, Vera A and Matacotta F C 1987 Phys. Rev. B36 7241

Blazey K W, Portis A M, Muller K A and Holtzberg F H 1988 Europhys. Lett. 6457

Blazey K W, Portis A M and Holtzberg F H 1989 Physica C157 16

Brivati J A, Stevens A D and Symons M C R $1990 \mathrm{~J}$. Mag. Res. (submitted)

Harutyunyan A R, Grigoryan L S, Baran M and Piechota S 1988 Phys. Lett. A133 339

Jones R, Janes R, Keeble D J, Singh K K and Edwards P P 1990 J. Chem. Soc. Faraday Trans. 84683

Lin T S, Sobotka L G and Froncisz W 1988 Nature (London) 33321

Lue J T and Wu C C 1989 Unpublished work

Peric M, Rakvin B, Prester M, Brnicevic N and Dulcic A 1988 Phys. Rev. B37 522

Suss J T, Berlinger W, Portis A M, Muller K A, Jeanneret B and Marinoli P 1989 Solid State Commun. 71929

Shrivastava K N 1988 Solid State Commun. 68259,1019

Tyagi S and Barsoum M 1988 Supercond. Sci. Technol. 120 